\title{
Meteorosensitivity as a mediator between affective temperaments and insomnia among women
}

\author{
Włodzimierz Oniszczenko (D) \\ Faculty of Psychology, University of Warsaw, Warsaw, Poland
}

\begin{abstract}
BACKGROUND
The main purpose of this cross-sectional study was to evaluate the associations between affective temperaments and insomnia symptoms in women and to examine meteorosensitivity as a mediator in this relationship.
\end{abstract}

\section{PARTICIPANTS AND PROCEDURE}

For this study, 446 healthy women were recruited from a nonclinical population via an online recruitment platform. The participants' ages ranged from 18 to 65 years $(M=29.67, S D=8.39)$. The Polish version of the Temperament Evaluation of Memphis, Pisa, Paris and San Diego Autoquestionnaire was used to assess affective temperaments (depressive, cyclothymic, hyperthymic, irritable and anxious). Meteorosensitivity was assessed through the Polish adaptation of the METEO-Q questionnaire. Insomnia was evaluated by the Athens Insomnia Scale.

\section{RESULTS}

Positive correlations with insomnia were found for meteorosensitivity, depressive, cyclothymic, irritable, and anxious temperaments, while insomnia negatively correlated with hyperthymic temperament. Meteorosensitivity showed positive correlations with depressive, cyclothymic, irritable, and anxious temperaments. No correlation between meteorosensitivity and hyperthymic temperament was found in the studied group. Based on the regression coefficients, meteorosensitivity, cyclothymic temperament and anxious temperament were found to be significant predictors of insomnia. Mediation analyses indicated that cyclothymic and anxious temperaments affected insomnia symptoms both directly and indirectly through meteorosensitivity as a mediator.

\section{CONCLUSIONS}

The results indicated a significant relationship between affective temperaments and insomnia symptoms, including the role of meteorosensitivity dimension as a mediator. These findings suggest that mood-related affective temperaments can also be associated with meteorosensitivity and jointly affect the level of insomnia symptoms in women.

\section{KEY WORDS}

adults; insomnia; women; affective temperaments; meteorosensitivity

CORRESPONDING AUTHOR - Prof. Włodzimierz Oniszczenko, Faculty of Psychology, University of Warsaw, 5-7 Stawki Str., 00-183 Warsaw, Poland, e-mail: wlodek@psych.uw.edu.pl

AUthors' CONTRIBUtion - A: Study design · B: Data collection · C: Statistical analysis · D: Data interpretation ·

E: Manuscript preparation · F: Literature search · G: Funds collection

TO CITE THIS ARTICLE - Oniszczenko, W. (2020). Meteorosensitivity as a mediator between affective temperaments

and insomnia among women. Current Issues in Personality Psychology, 8(4), 301-308.

RECEIVED 27.05.2020 • REVIEWED 20.08.2020 • ACCEPTED 21.10.2020 • PUBLISHED 27.11.2020 


\section{BACKGROUND}

Numerous studies have indicated that the risk of sleep disturbances and insomnia is higher in women than in men. Researchers have also observed that, compared to men, women more often develop depression and anxiety disorders associated with insomnia (Krystal, 2003). In fact, long-term insomnia may increase the likelihood of depression and anxiety disorders (Li, Wu, Gan, Qu, \& Lu, 2016; Neckelmann, Mykletun, \& Dahl, 2007; Rumble, White, \& Benca, 2015). According to Alvaro, Roberts, and Harris (2013), the relationship between insomnia and depressive and anxiety disorders is two-sided. In other words, insomnia leads to the development of these disorders but can also be a consequence of depression and anxiety. Considerable evidence shows that depression occurs twice as often in women compared to men and that hormonal changes may play an important role in the development of depression symptoms in women (Albert, 2015; Payne, 2003; Steiner, Yonkers, \& Eriksson, 2001). Women are also more likely to develop an anxiety disorder compared to men (McLean, Asnaani, Litz, \& Hofmann, 2011; Bandelow \& Michaelis, 2015).

Scholars have considered affective temperaments (depressive, cyclothymic, hyperthymic, irritable and anxious) to be risk factors for developing such mood disorders as depression, anxiety and bipolar disorder (Akiskal \& Akiskal, 2005; DeGeorge, Walsh, Barrantes-Vidal, \& Kwapil, 2014). According to Kawamura et al. (2010) affective temperaments can be considered stable over time and associated with sleep disorders. For example, Rovai et al. (2013) defined hyperthymics as individuals with little need to sleep and indicated that cyclothymic temperament is associated with a reduced need for sleep alternating with hypersomnia. In terms of their correlation with insomnia symptoms in general, depressive, cyclothymic, irritable and anxious affective temperaments correlate positively, while hyperthymic temperament shows a negative correlation (Oniszczenko, Rzeszutek, \& Stanisławiak, 2019).

Insomnia is one of the symptoms of meteoropathy (Mazza et al., 2012). Janiri, Spinetti, Mazza, and Di Nicola (2009) defined meteoropathy as the set of symptoms that occur in the human body in response to gradual or sudden changes in meteorological conditions at a given location. The most frequent meteoropathy symptoms - mood disturbances, irritability, a desire to remain indoors, mental and physical weakness, cardiovascular symptoms, headache, insomnia and susceptibility to pain - may appear before the arrival of a weather change and last for one or two days. Significant individual differences in sensitivity to weather changes are possible. The key concept, in this case, is meteorosensitivity, which is defined as the susceptibility of the subject to the action of one or more meteorological phenomena. According to Mazza et al. (2012), meteorosensitivity describes the individually differing susceptibility to the impact of meteorological events that may, to a varying degree, cause new mental and somatic disorders or lead to the worsening of existing maladies. Freti et al. (2017) asserted that human psychophysical reactivity (i.e. meteorosensitivity) and the ability to manage psychological stress affect the development of meteoropathy. A disturbance in these mechanisms can lead to the development of somatic symptoms typical of meteoropathy.

Based on Janiri et al.'s (2009) findings that people with depression and anxiety are more prone to meteoropathy, and given that many symptoms of meteoropathy (e.g. mood disorders, irritability and insomnia) are present in the characteristics of affective temperaments, affective temperaments may presumably be associated with the degree of meteorosensitivity and play a vital role in the development of symptoms of meteoropathy, including insomnia. The available data have indicated that women demonstrate higher levels of depressive, cyclothymic and anxious temperaments compared to men (Blöink, Brieger, Akiskal, \& Marneros, 2005; Oniszczenko, Stanisławiak, Dembińska-Krajewska, \& Rybakowski, 2017; Vázquez, Tondo, Mazzarini, \& Gonda, 2012) as well as higher levels of meteorosensitivity and meteoropathy in comparison to males (Mazza et al., 2012).

For this investigation, we assumed that affective temperaments can directly affect an individual's insomnia level but can also interact indirectly, that is, increase the level of meteorosensitivity and consequently intensify insomnia symptoms. The purpose of this study, therefore, was to assess the relationship between affective temperaments and insomnia symptoms and to examine meteorosensitivity as a mediator in this relationship in women. We expected that high levels of depressive, cyclothymic and anxious temperaments would be associated directly and indirectly with insomnia symptoms in women, with meteorosensitivity as a mediator between them.

To our knowledge, this was the first attempt to link affective temperaments with meteorosensitivity and insomnia as one of the symptoms of meteoropathy in women in a nonclinical population.

\section{PARTICIPANTS AND PROCEDURE}

\section{PARTICIPANTS}

For this study, 446 healthy women were recruited from a nonclinical population via an online recruitment platform. The participants' ages ranged from 18 to 65 years $(M=29.67, S D=8.39)$.

The study was part of a larger research project on personality and temperamental determinants of me- 
teorosensitivity and their relationship with insomnia symptoms. Data collection took place between January 2019 and March 2019.

The study was anonymous and voluntary, and the participants received no remuneration. Informed consent was obtained from all participants before inclusion in the study. The research project was approved by the local Research Ethics Commission at the Faculty of Psychology, University of Warsaw, Poland.

\section{MEASURES}

Temperament Evaluation of Memphis, Pisa, Paris, and San Diego Autoquestionnaire. Borkowska et al.'s (2010) Polish adaptation of the Temperament Evaluation of Memphis, Pisa, Paris, and San Diego Autoquestionnaire (TEMPS-A; Akiskal, Akiskal, Haykal, Manning, \& Connor, 2005) was used to diagnose five affective temperaments. Cronbach's alphas for the current sample are shown in parentheses: depressive (.73), cyclothymic (.83), hyperthymic (.81), irritable (.84) and anxious (.87). The TEMPS-A is a self-report instrument comprising 110 items (109 for men) using a yes/no response format. For each answer, a 'yes' response was scored as 1 and a 'no' response as 0.

Athens Insomnia Scale. Fornal-Pawłowska, Wołyńczyk-Gmaj, and Szelenberge's Polish adaptation (2011) of the Athens Insomnia Scale (AIS; Soldatos, Dikeos, \& Paparrigopoulos, 2000) was used to assess insomnia symptoms. The AIS consists of eight items, scoring from 0 to 3 . The total score for the scale ranges from 0 to 24 . Higher values indicate unsatisfactory sleep quality, denoting insomnia. The Cronbach's $\alpha$ value for the current sample was .84.

METEO-Q questionnaire. Oniszczenko's (2019) Polish adaptation of the METEO-Q questionnaire (Mazza et al., 2012) was used to diagnose meteorosensitivity. This questionnaire consists of 11 items that measure meteorosensitivity (5 items) and meteoropathy (6 items), rated on a 4-point Likert scale ranging from 0 (absent) to 3 (severe). The value of Cronbach's $\alpha$ for the meteorosensitivity scale was .77 for the current sample. Only the meteorosensitivity scale was analysed in this study, as this study did not consider meteoropathy.

\section{STATISTICAL ANALYSIS}

Statistical analysis was performed using IBM SPSS Statistics 25 . The relationships among variables were examined with Pearson product-moment coefficients. Hierarchical regression analysis was employed to estimate the effect of meteorosensitivity and affective temperaments as predictors of insomnia symptoms. The mediation analyses were conducted via the
PROCESS macro for SPSS v. 3.3, Model 4 (Hayes, 2018). In addition, a bootstrapping procedure with 5,000 sample draws and bias-corrected standard errors was used to estimate the direct and indirect effects (Preacher \& Hayes, 2008).

\section{RESULTS}

Table 1 shows the sociodemographic characteristics of the study sample.

Table 2 presents the basic descriptive statistics for the insomnia, meteorosensitivity and affective temperaments scales. As the table illustrates, skewness and kurtosis analysis showed a normal distribution for all variables. Skewness varied from .11 (hyperthymic temperament) to .63 (insomnia symptoms), while kurtosis ranged from -.73 (hyperthymic temperament) to .03 (insomnia symptoms).

Table 3 displays the Pearson $r$ correlation coefficients among age, insomnia, meteorosensitivity and the affective temperament traits. Correlations among all variables studied ranged from small to large (absolute value of $r$ of .1 was classified as small, .3 as medium and .5 as large; Cohen, 1988).

As Table 3 shows, a positive correlation with participants' ages emerged only for hyperthymic temperament, while cyclothymic, irritable and anxious temperaments correlated negatively with age. No correlations between age and the other variables were apparent.

Insomnia was positively correlated with meteorosensitivity as well as depressive, cyclothymic, irritable and anxious temperaments but correlated negatively with hyperthymic temperament.

Table 1

Sociodemographic variables in the studied sample $(N=446)$

\begin{tabular}{lc}
\hline Variables & Participants \\
\hline $\begin{array}{l}\text { Sex, } n(\%) \\
\text { Women }\end{array}$ & $446(100)$ \\
Education, $n(\%)$ & $300(67.3)$ \\
$\quad$ Higher & $145(32.5)$ \\
Secondary & $1(0.2)$ \\
Primary & \\
Place of residence, $n(\%)$ & $58(13.0)$ \\
Rural areas & $65(14.6)$ \\
Small towns & $323(72.4)$ \\
Large cities &
\end{tabular}


Table 2

Descriptive statistics for insomnia and meteorosensitivity and the Temperament Evaluation of Memphis, Pisa, Paris and San Diego Autoquestionnaire scales $(N=446)$

\begin{tabular}{lcccc}
\hline & Range & $M(S D)$ & Skewness & Kurtosis \\
\hline Insomnia & $0-24$ & $8.77(4.70)$ & .63 & .03 \\
Meteorosensitivity & $0-15$ & $9.47(3.10)$ & -.54 & .21 \\
Affective temperaments & & & .26 & -.51 \\
$\quad$ Depressive & $.00-.95$ & $0.44(0.18)$ & .20 & -.69 \\
$\quad$ Cyclothymic & $.00-.95$ & $0.42(0.22)$ & .11 & -.73 \\
Hyperthymic & $.00-.95$ & $0.43(0.21)$ & .53 & -.38 \\
$\quad$ Irritable & $.00-.95$ & $0.31(0.21)$ & .28 & -.57 \\
$\quad$ Anxious & $.00-1.00$ & $0.42(0.23)$ & & .28 \\
\hline
\end{tabular}

Table 3

Pearson's r correlations between age, insomnia, meteorosensitivity and Temperament Evaluation of Memphis, Pisa, Paris and San Diego Autoquestionnaire scales $(N=446)$

\begin{tabular}{|c|c|c|c|c|c|c|c|}
\hline Variable & 2 & 3 & 4 & 5 & 6 & 7 & 8 \\
\hline 1. Age & .00 & .01 & -.08 & $-.22^{* * *}$ & $.10^{*}$ & $-.17^{* * *}$ & $-.14^{* *}$ \\
\hline 2. Insomnia & & $.25^{* * *}$ & $.34^{* * *}$ & $.42^{* * *}$ & $-.17^{* * *}$ & $.25^{* * *}$ & $.46^{* * *}$ \\
\hline 3. Meteorosensitivity & & & $.17^{* * *}$ & $.33^{* * *}$ & .02 & $.25^{* * *}$ & $.30^{* * *}$ \\
\hline 4. Depressive & & & & $.56^{* * *}$ & $-.60^{* * *}$ & $.44^{* * *}$ & $.67^{* * *}$ \\
\hline 5. Cyclothymic & & & & & $-.21^{* * *}$ & $.67^{* * *}$ & $.61^{* * *}$ \\
\hline 6. Hyperthymic & & & & & & $-.20^{* * *}$ & $-.43^{* * *}$ \\
\hline 7. Irritable & & & & & & & $.50^{* * *}$ \\
\hline 8. Anxious & & & & & & & 1.00 \\
\hline
\end{tabular}

Positive correlations with meteorosensitivity were found for depressive, cyclothymic, irritable and anxious temperaments. No correlation between meteorosensitivity and hyperthymic temperament was revealed in the studied group.

To determine the extent to which meteorosensitivity and affective temperaments can be viewed as predictors of insomnia, we conducted a hierarchical multiple regression analysis. Meteorosensitivity was entered in Step 1 of this analysis, explaining 6\% of the variance in insomnia symptoms in the whole sample. When the five affective temperaments were added in Step 2, the percentage of variance accounted for increased to $25 \%, F(6,439)=25.42, p<.001$. Based on the regression coefficients, meteorosensitivity $(\beta=.10, p<.05)$, cyclothymic temperament $(\beta=.27$, $p<.001)$ and anxious temperament $(\beta=.33, p<.001)$ were found to be significant predictors of insomnia. Table 4 summarises these results.

Two separate analyses were performed using a bootstrapping procedure and with meteorosen- sitivity as the mediator between cyclothymic and anxious temperaments and insomnia in the studied group. The first analysis revealed a significant indirect effect of cyclothymic temperament on insomnia through meteorosensitivity as a mediator [effect $=.90, S E=.38,95 \% \mathrm{CI}=(0.21,1.71)]$. The second analysis found a significant indirect effect of anxious temperament on insomnia symptoms through meteorosensitivity as a mediator [effect $=.78, S E=.34$, $95 \% \mathrm{CI}=(0.17,1.51)]$. See Figure 1 for the individual pathways in the mediation analysis.

\section{DISCUSSION}

Our data reveal that two affective temperaments, cyclothymic and anxious, were the best predictors of insomnia symptoms in the studied group of women. Our results coincide with Akiskal et al.'s (2005) description of these two temperaments, pointing to their potential role in the formation and development 
Table 4

Hierarchical multiple regression analysis of meteorosensitivity and affective temperaments as predictors of insomnia in the whole sample $(N=446)$

\begin{tabular}{|c|c|c|c|c|c|c|}
\hline Variables & $B$ & $S E B$ & $\beta$ & $\begin{array}{c}\text { Corrected } \\
R^{2} \\
\end{array}$ & $\Delta R^{2}$ & $\begin{array}{l}\text { Semi-partial } \\
\text { correlations }\end{array}$ \\
\hline Step 1 & & & & .06 & & \\
\hline Meteorosensitivity & 0.38 & 0.07 & $.25^{* *}$ & & & .25 \\
\hline Step 2 & & & & .25 & $.19^{* * *}$ & \\
\hline Meteorosensitivity & 0.14 & 0.07 & $.10^{*}$ & & & .09 \\
\hline Depressive & 0.33 & 1.68 & .01 & & & .01 \\
\hline Cyclothymic & 5.65 & 1.37 & $.27^{* * *}$ & & & .17 \\
\hline Hyperthymic & 0.19 & 1.17 & .01 & & & .01 \\
\hline Irritable & -2.79 & 1.26 & $-.12^{*}$ & & & -.09 \\
\hline Anxious & 6.71 & 1.27 & $.33^{* * *}$ & & & .22 \\
\hline
\end{tabular}
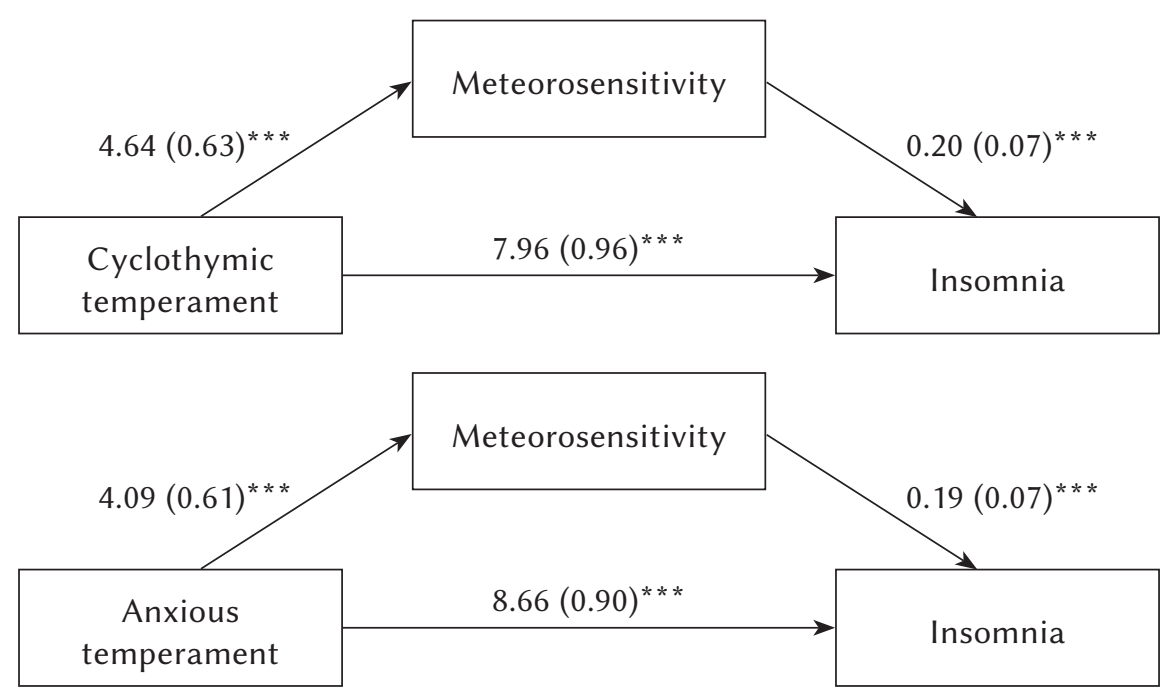

Note. ${ }^{* * *} p<.001$.

Figure 1. Mediating effect of meteorosensitivity in the relationship between cyclothymic temperament and insomnia (upper) and in the relationship between anxious temperament and insomnia (lower) in a sample of women. Unstandardised coefficients are reported, with standard errors in parentheses.

of sleep disorders. Research has characterised cyclothymic temperament as associated with unexplained changes in mood, sudden changes in energy and alternating changes in sleep demand, ranging from decreased need for sleep to excessive sleep demand. As Walsh, Brown, Barrantes-Vidal, and Kwapil (2013) indicated, cyclothymic/irritable temperament is strongly associated with reactivity to stress in everyday life, potentially exacerbating the symptoms of insomnia in women. The second temperament, anxious, primarily involves excessive vigilance, tension and irritability, which is the result of an increased level of autonomic arousal. Interestingly, depressive affective temperament was not a significant predictor of insomnia in our sample, although previous studies have frequently observed a strong association between depression and insomnia (Oh, Kim, Na, Cho, \& Chu, 2019).

The biological basis of the direct relationship between affective temperaments and insomnia can be found in serotonin and the functioning of the autonomic nervous system (ANS). Vázquez and Gonda (2013) emphasised that the results of molecular genetics studies have indicated a strong association of the four affective temperaments (depressive, cyclothymic, irritable and anxious) with serotonergic gene polymorphisms, and hyperthymic temperament with dopaminergic polymorphisms. Studies in mice (Brindley, Bauer, Blakely, \& Currie, 2017) and studies 
in the human population (Chang et al., 2018) have suggested links between serotonin and the functioning of the ANS. According to Leonard (2005), serotonin is also involved in the reactions of the hypothalamic-pituitary-adrenal axis, which is significant in the development of depression and anxiety, and which (through the hypothalamus) is associated with stimulation of the ANS. The activation of the sympathetic part of the ANS is associated with responses to acute and chronic stress and an increase in arousal, leading to sleep disorders.

A new and key finding that emerged from our analysis was that affective temperaments are associated with meteorological sensitivity (i.e. the subject's susceptibility to one or more meteorological phenomena). Meteorosensitivity is strongly related to the level of meteoropathy (Oniszczenko, 2019). Of the twenty manifestations of meteoropathy identified by Mazza et al. (2012), half seem to result directly from the characteristics of affective temperaments (e.g. lability of mood, anxiety, depression, irritability, indefinite feeling of malaise) and others from the influence of the ANS (tachycardia, lack of or excessive appetite, insomnia). Our results suggest that cyclothymic and anxious temperaments, in particular, may contribute to increased sensitivity to weather phenomena and affect the severity of meteoropathy symptoms, including insomnia. As Freti et al. (2017) suggested, meteorosensitive subjects display some difficulties in coping with psychophysical perturbations arising from meteorological events. According to the authors, the action of meteorological factors and other stressors can make maintaining a balance of physiological variables difficult. This imbalance may lead to the development of somatic symptoms with no organic explanation in meteorosensitive individuals. Our results suggest that cyclothymic and anxious temperaments, in particular, may contribute to an increase in the level of symptoms related to meteorosensitivity and meteoropathy, including insomnia.

Mediation analysis showed both a direct and indirect relationship between cyclothymic and anxious temperament and symptoms of insomnia in women, mediated by meteorological sensitivity. Presumably, then, meteorological sensitivity may play an important role as a mediator between personality symptoms and insomnia and other psychosomatic disorders. However, understanding the common biological mechanisms of affective temperaments, meteorological sensitivity and insomnia presents a challenge. Seemingly, ANS reactivity, along with brain activation mechanisms, can be viewed as an essential common basis for all three variables. As Ziemssen and Siepmann (2019) noted, the ANS innervates all organs of the body and is involved in almost all diseases. Meteorosensitivity is a mediator between affective temperaments and insomnia. Affective temperaments, due to the increased level of human sensitivity to meteorological factors related to the nervous mechanisms - central and autonomic - consequently intensify the symptoms of insomnia.

The present study has limitations that must be considered. The research is cross-sectional in design. This type of research makes it impossible to formulate conclusions regarding directional relationships between the studied variables. Further longitudinal studies are necessary to confirm the hypothesis about the role of affective temperaments and meteorosensitivity in the development of insomnia symptoms in women. We used only self-reported data without documenting the presence of comorbid physical and mental health disorders or substance use in the studied group. Therefore, our results must be interpreted with caution.

\section{CONCLUSIONS}

Cyclothymic and anxious temperaments, as well as meteorosensitivity, were the best predictors of insomnia symptoms in the studied group. Meteorosensitivity mediated between affective temperaments and insomnia symptoms in women.

\section{ACKNOWLEDGEMENTS}

This work was supported by the Faculty of Psychology, University of Warsaw, from the funds awarded by the Ministry of Science and Higher Education in the form of a subsidy for the maintenance and development of research potential in 2020 No 501-D12501-1250000.

This research did not receive any specific grant from funding agencies in the public, commercial or not-for-profit sectors.

\section{REFERENCES}

Akiskal, H. S., Akiskal, K. K., Haykal, R. F., Manning, J. S., \& Connor, P. D. (2005). TEMPS-A: Progress towards validation of a self-rated clinical version of the Temperament Evaluation of the Memphis, Pisa, Paris, and San Diego Autoquestionnaire. Journal of Affective Disorders, 85, 3-16. https://doi.org/10.1016/j.jad.2004.12.001

Akiskal, K. K., \& Akiskal, H. S. (2005). The theoretical underpinnings of affective temperaments: Implications for evolutionary foundations of bipolar disorder and human nature. Journal of Affective Disorders, 85, 231-239. https://doi.org/10.1016/j. jad.2004.08.002

Albert, P. R. (2015). Why is depression more prevalent in women? Journal of Psychiatry \& Neuroscience, 40, 219-221. https://doi.org/10.1503/jpn.150205 
Alvaro, P. K., Roberts, R. M., \& Harris, J. K. A. (2013). A systematic review assessing bidirectionality between sleep disturbances, anxiety, and depression. Sleep, 36, 1059-1068. https://doi.org/10.5665/ sleep. 2810

Bandelow, B., \& Michaelis, S. (2015). Epidemiology of anxiety disorders in the 21st century. Dialogues in Clinical Neurosciences, 17, 327-335.

Blöink, R., Brieger, P., Akiskal, H. S., \& Marneros, A. (2005). Factorial structure and internal consistency of the German TEMPS-A scale: Validation against the NEO-FFI questionnaire. Journal of Affective Disorders, 85, 77-83. https://doi. org/10.1016/S0165-0327(03)00101-0

Borkowska, A., Rybakowski, J. K., Drożdż, W., Bieliński, M., Kosmowska, M., Rajewska-Rager, A., Bucinski, A., Akiskal, K. K., \& Akiskal, H. S. (2010). Polish validation of the TEMPS-A: The profile of affective temperaments in a college student population. Journal of Affective Disorders, 123, 36-41. https://doi.org/10.1016/j.jad.2009.09.024

Brindley, R. L., Bauer, M. B., Blakely, R. D., \& Currie, K. (2017). Serotonin and serotonin transporters in the adrenal medulla: a potential hub for modulation of the sympathetic stress response. ACS Chemical Neuroscience, 8, 943-954. https://doi. org/10.1021/acschemneuro.7b00026

Chang, W. H., Lee, I. H., Chi, M. H., Lin, S. H., Chen, K. C., Chen, P. S., Chiu, N. T., Yao, W. J., \& Yang, Y. K. (2018). Prefrontal cortex modulates the correlations between brain-derived neurotrophic factor level, serotonin, and the autonomic nervous system. Scientific Reports, 8, article 2558. https://doi.org/10.1038/s41598-018-20923-y

Cohen, J. (1988). Statistical power analysis for the behavioral sciences (2nd ed.). Hillsdale, NJ: Erlbaum.

DeGeorge, D. P., Walsh, M. A., Barrantes-Vidal, N., \& Kwapil, T. R. (2014). A three-year longitudinal study of affective temperaments and risk for psychopathology. Journal of Affective Disorders, 164, 94-100. https://doi.org/10.1016/j.jad.2014.04.006

Fornal-Pawłowska, M., Wołyńczyk-Gmaj, D., \& Szelenberger, W. (2011). Validation of the Polish version of the Athens Insomnia Scale. Psychiatria Polska, 45, 211-221.

Freti, L., Condemi, V., Mazza, M., Di Nicola, M., Janiri, L., Antonietti, A., Gestro, M., \& Solimene, U. (2017). Meteorosensitivity in a group of patients affected by multiple sclerosis and hospitalized in a rehabilitation facility: an observational study. Alternative and Integrative Medicine, 6, article 252. https://doi.org/10.4172/2327-5162.1000252

Hayes, A. F. (2018). Introduction to mediation, moderation, and conditional process analysis: a regressionbased approach (2nd ed.). New York, NY: Guilford Press.

Janiri, L., Spinetti, G., Mazza, M., \& Di Nicola, M. (2009). Meteoropathy. A new disease. In G. N. Christodou- lou, M. Jorge, \& J. E. Mezzich (Eds.), Advances in psychiatry (Vol. 3, pp. 45-52). Athens: Beta Medical Publishers.

Kawamura, Y., Akiyama, T., Shimada, T., Minato, T., Umekage, T., Noda, Y., Ukawa, K., Hashidume, C., Sakai, Y., Otowa, T., Sasaki, T., \& Akiskal, H. S. (2010). Six-year stability of affective temperaments as measured by TEMPS-A. Psychopathology, 43, 240-247. https://doi.org/10.1159/000313522

Krystal, A. D. (2003). Insomnia in women. Clinical Cornerstone, 5, 41-50. https://doi.org/10.1016/S10983597(03)90034-2

Leonard, B. E. (2005). The HPA and immune axes in stress: The involvement of the serotonergic system. European Psychiatry, 20, S302-S306. https:// doi.org/10.1016/S0924-9338(05)80180-4

Li, L., Wu, C., Gan, Y., Qu, X., \& Lu, Z. (2016). Insomnia and the risk of depression: a meta-analysis of prospective cohort studies. BMC Psychiatry, 16, article 375. https://doi.org/10.1186/s12888-016-1075-3

Mazza, M., Di Nicola, M., Catalano, V., Callea, A., Martinotti, G., Harnic, D., Bruschi, A., Battaglia, C., \& Janiri, L. (2012). Description and validation of a questionnaire for the detection of meteoropathy and meteorosensitivity: the METEO-Q. Comprehensive Psychiatry, 53, 103-106. https://doi.org/ 10.1016/j.comppsych.2011.02.002

McLean, C. P., Asnaani, A., Litz, B. T., \& Hofmann, S. G. (2011). Gender differences in anxiety disorders: Prevalence, course of illness, comorbidity and burden of illness. Journal of Psychiatry Research, 45, 1027-1035. https://doi.org/10.1016/j. jpsychires.2011.03.006

Neckelmann, D., Mykletun, A., \& Dahl, A. A. (2007). Chronic insomnia as a risk factor for developing anxiety and depression. Sleep, 30, 873-880. https:// doi.org/10.1093/sleep/30.7.873

Oh, C. M., Kim, H.Y., Na, H. K., Cho, K. H., \& Chu, M. K. (2019). The effect of anxiety and depression on sleep quality of individuals with high risk for insomnia: a population-based study. Frontiers in Neurology, 10, article 849. https://doi.org/10.3389/fneur.2019.00849

Oniszczenko, W. (2019). Validation of the Polish version of the METEO-Q questionnaire. Unpublished raw data.

Oniszczenko, W., Rzeszutek, M., \& Stanisławiak, E. (2019). Affective temperaments, mood, and insomnia symptoms in a nonclinical sample. Behavioral Sleep Medicine, 17, 355-363. https://doi.org/ 10.1080/15402002.2017.1357121

Oniszczenko, W., Stanisławiak, E., Dembińska-Krajewska, D., \& Rybakowski, J. (2017). Regulative theory of temperament versus affective temperaments measured by the Temperament Evaluation of Memphis, Pisa, Paris and San Diego Auto-questionnaire (TEMPS-A): a study in a non-clinical Polish sample. Current Issues in Personality Psychology, 5, 73-82. https://doi.org/10.5114/cipp.2017.65847 
Payne, J. L. (2003). The role of estrogen in mood disorders in women. International Review of Psychiatry, 15, 280-290. https://doi.org/10.1080/0954026031000 136893

Preacher, K. J., \& Hayes, A. F. (2008). Asymptotic and resampling strategies for assessing and comparing indirect effects in multiple mediator models. $\mathrm{Be}$ havioral Research Methods, 40, 879-891. https://doi. org/10.3758/BRM.40.3.879

Rovai, L., Maremmani, A. G., Rugani, F., Bacciardi, S., Pacini, M., Dell'Osso, L., Akiskal, H. S., \& Maremmani, I. (2013). Do Akiskal \& Mallya's affective temperaments belong to the domain of pathology or to that of normality? European Review for Medical and Pharmacological Sciences, 17, 2065-2079.

Rumble, M. E., White, K. H., \& Benca, R. M. (2015). Sleep disturbances in mood disorders. Psychiatric Clinics of North America, 38, 743-759. https://doi. org/10.1016/j.psc.2015.07.006

Soldatos, C. R., Dikeos, D. G., \& Paparrigopoulos, T. J. (2000). Athens Insomnia Scale: Validation of an instrument based on ICD-10 criteria. Journal of Psychosomatic Research, 48, 555-560. https://doi. org/10.1016/s0022-3999(00)00095-7

Steiner, M., Yonkers, K. A., \& Eriksson E. (Eds.). (2001). Mood disorders in women. London: CRC Press.

Vázquez, G. H., \& Gonda, X. (2013). Affective temperaments and mood disorders: a review of current knowledge. Current Psychiatry Reviews, 9, 21-32. https://doi.org/10.2174/1573400511309010004

Vázquez, G. H., Tondo, L., Mazzarini, L., \& Gonda, X. (2012). Affective temperaments in general population: A review and combined analysis from national studies. Journal of Affective Disorders, 139, 18-22. https://doi.org/10.1016/j.jad.2011.06.032

Walsh, M. A., Brown, L. H., Barrantes-Vidal, N., \& Kwapil, T. R. (2013). The expression of affective temperaments in daily life. Journal of Affective Disorders, 145, 179-186. https://doi.org/10.1016/j. jad.2012.07.026

Ziemssen, T., \& Siepmann, T. (2019). The investigation of the cardiovascular and sudomotor autonomic nervous system - a review. Frontiers in Neurology, 10, article 53. https://doi.org/10.3389/ fneur.2019.00053 